\title{
Resenha \\ Cidadania Multicultural. Uma teoria liberal dos direitos das minorias
}

KYMLICKA, Will. Cidadania multicultural. Uma teoria liberal dos direitos das minorias. Barcelona: Ediciones Paidós, 1996. Tradução Isabel Cristina Brettas Duarte.

Versão original:

KYMLICKA, Will. Ciudadanía multicultural. Una teoría liberal de los derechos de las minorías. Barcelona: Ediciones Paidós, 1996.

\author{
Isabel Cristina Brettas Duarte \\ Doutoranda em Direito pela URI/Campus de Santo Ângelo/RS. \\ Advogada da Procuradoria-Geral do Município de Santo Ângelo. isabelcristinabd@yahoo.com.br
}

RESUMO

O livro do filósofo canadense Will Kymlicka, pelo fato de ainda não ter sido traduzido e publicado no Brasil, carece de fortuna crítica no país, razão pela qual a presente resenha, ora traduzida por esta autora da Língua Espanhola para a Língua Portuguesa, pode servir de aporte introdutório à obra do referido autor, cujo reconhecimento de suas contribuições tem se dado em âmbito mundial, principalmente na Europa. No livro em questão, Kymlicka aborda como uma teoria liberal dos direitos das minorias deve explicar a coexistência dos direitos das minorias com os direitos humanos, e também como os direitos das minorias estão limitados por princípios de liberdade individual, democracia e justiça social, na perspectiva de um multiculturalismo liberal que complementa os princípios tradicionais dos direitos humanos com uma teoria dos direitos das minorias. Entende que é preciso complementar os direitos humanos tradicionais com os direitos das minorias, pois em um Estado multicultural, uma teoria da justiça deve abarcar tanto os direitos universais, relativos aos indivíduos independentemente do seu grupo de pertencimento, quanto envolver também determinados direitos diferenciados de grupos, de modo a conceder um status especial para as culturas minoritárias.

Palavras-chave: Direitos das minorias. Cidadania multicultural.

ABSTRACT

The book by the Canadian philosopher Will Kymlicka, because it has not been translated and published in Brazil, lacks of water translated into this language. The first, their support from their partners has been given around the world, especially in Europe. Not book in question, Kymlicka approaches as a liberal theory of the rights of minorities developing a coexistence The rights of minorities with human rights, as well as the rights of minorities, are limited by principles of individual liberty, democracy and social justice, in the perspective of a liberal multiculturalism that It complements the Classics of human rights with a theory of minority rights. You see which is a complement to human rights with the rights of minorities multicultural society, a theory of justice must embrace universal rights of your membership group, particular status for minority cultures.

Keywords: Rights of minorities. Multicultural citizenship.

SUMÁRIO

1 Questionamentos Norteadores do Pensamento do Autor. 2 As Políticas do Multiculturalismo. 2.1 Estados Multinacionais e Estados Poliétnicos. 2.2 Três Formas de Direitos Diferenciados em Função do Grupo. 3 Direitos Individuais e Direitos Coletivos. 3.1 Restrições Internas e Proteções Externas. 3.2 A Ambiguidade dos Direitos Coletivos. 4 Repensando a Tradição Liberal. 5 Liberdade e Cultura. 6 A Justiça e os Direitos das Minorias. 7 Assegurar a Voz das Minorias. 7.1 Por que a Representação de Grupo? 7.2 Valoração da Representação de Grupo. 8 A Tolerância e seus Limites. 8.1 Liberalismo e Tolerância. 8.2 Como Acomodar as Minorias Não Liberais? 9 Os Vínculos que Unem. 9.1 A Importância da Cidadania. 9.2 Autogoverno e Separatismo. 9.3 As Bases da Unidade Social em um Estado Multinacional. 10 Conclusão. 11 Referências. 


\section{Humanos}

Democracia

\section{Questionamentos Norteadores do Pensamento do Autor}

Kymlicka parte do pressuposto de que, na atualidade, a maioria dos países são culturalmente diversos, e que tal diversidade traz uma série de questões importantes, pois minorias e maiorias enfrentam-se cada vez mais no que diz respeito a temas como os direitos linguísticos, a autonomia regional, a representação política, o currículo educativo, as reivindicações territoriais, a política de imigração e naturalização, e incluindo símbolos nacionais, como a eleição do Hino Nacional e as festividades oficiais (p. 13).

Assim, entende que encontrar respostas moralmente defensáveis e politicamente viáveis a tais discussões constitui o principal desafio das democracias na atualidade. Cada disputa possui história e circunstâncias únicas e intransferíveis que devem ser consideradas no momento de criar uma solução justa e viável. Por isso, o objetivo do autor é identificar alguns conceitos e princípios-chave, esclarecendo os fundamentos básicos do enfoque liberal do problema dos direitos das minorias.

Para alcançar o ideal de uma sociedade e organização política homogênea, os governos, ao longo da História, seguiram diversas políticas a respeito das minorias culturais, variando desde a eliminação até as expulsões maciças e ao genocídio. Outras minorias foram assimiladas coercitivamente, e forçadas a adotar a língua, a religião e os costumes da maioria. Em outros casos, as minorias foram tratadas como estrangeiros residentes, submetidas à segregação física e à discriminação econômica, bem como à privação dos direitos políticos.

Após a Segunda Guerra Mundial restou evidente que a questão dos direitos das minorias deveria ser abordada de forma diferente. Muitos liberais acreditavam que a nova ênfase nos direitos humanos básicos (liberdade de expressão, associação e consciência) resolveria os conflitos das minorias, as quais seriam protegidas indiretamente na medida em que estivessem garantidos os direitos civis e políticos básicos a todos os indivíduos, independentemente do seu grupo de pertencimento. Os liberais deram por certo que, por proteger tais direitos individuais, não seria necessário atribuir direitos adicionais a membros de minorias étnicas ou nacionais específicas.

A maioria dos liberais do pós-guerra continua rechaçando a ideia de uma diferenciação permanente dos direitos dos membros de determinados grupos. Ou seja, rebatem a afirmação de que os direitos específicos de determinados grupos são necessários para reconciliar diferenças culturais tradicionais, ainda mais do que para remediar discriminações históricas, opondo-se à ideia de conceder aos grupos étnicos ou nacionais específicos uma identidade política permanente ou um status constitucional.

Kymlicka, no entanto, entende que os direitos das minorias não podem ser resumidos sob a categoria dos direitos humanos, cujas pautas e procedimentos tradicionais são incapazes de resolver as controvertidas questões relativas às minorias culturais, por exemplo:

Quais línguas deveriam ser aceitas nos Parlamentos e Tribunais? Deve-se dedicar fundos públicos para escolarizar a língua materna a todos os grupos étnicos e nacionais? Deve-se traçar fronteiras internas para lograr que as minorias culturais formem uma maioria dentro de uma região local? Deve-se devolver poderes governamentais em nível central a níveis centrais ou regionais controlados por minorias concretas, especialmente em temas delicados, como a imigração, as comunicações e a educação? Deve-se distribuir os orga- 
nismos políticos de acordo com um princípio de proporcionalidade nacional ou étnica? Deve-se conservar e proteger os lugares de origem tradicional dos povos indígenas para seu exclusivo benefício? Que grau de integração cultural pode ser exigidos dos imigrantes e dos refugiados antes que adquiram a cidadania? (p. 17-18).

A partir de tais questionamentos Kymlicka desenvolve a obra sub oculis em dez capítulos, expostos resenhadamente na sequência em suas ideias centrais.

\section{As Políticas do Multiculturalismo}

Este é o título do segundo capítulo da obra, o qual objetiva distinguir Estados multinacionais de Estados poliétnicos, bem como diferenciar minorias nacionais (em Estados multiétnicos) e grupos étnicos (em Estados poliétnicos) e, por fim, relacionar raça, etnia e nacionalidade, de modo a centrar o capítulo em dois modelos de diversidade cultural.

Primeiramente, a diversidade cultural surge da incorporação de diversas culturas que anteriormente possuíam autogoverno e estavam concentradas territorialmente a um Estado maior (relacionada a Estados multinacionais). Denomina tais culturas incorporadas de minorias nacionais, apontando como sua característica distintiva o desejo de seguir sendo sociedades distintas da cultura maioritária da qual fazem parte.

Ainda, a diversidade cultural que surge da imigração individual e familiar (relacionada a Estados poliétnicos). Tais grupos étnicos (imigrantes que abandonaram sua comunidade nacional para incorporar-se a outra sociedade) desejam integrar-se à sociedade da qual fazem parte e ser aceitos como seus membros de pleno direito. Seu objetivo não é se converter em uma nação separada e autogovernada paralelamente à sociedade na qual estão inseridos, mas sim modificar as instituições e leis de tal sociedade para que seja mais permeável às diferenças culturais (p. 25-26).

O autor utiliza os adjetivos "multinacional" e "poliétnico" para aludir às duas formas principais de pluralismo cultural. Esclarece que utiliza a terminologia cultura (e multicultural) em um sentido diferente, centrado no tipo de multiculturalismo derivado das diferenças nacionais e étnicas. Utiliza cultura como sinônimo de nação ou povo, ou seja, como uma comunidade mais ou menos completa institucionalmente, que ocupa um território ou uma pátria determinada e compartilha uma língua e uma história específicas. Um Estado, portanto, é multicultural se seus membros pertencem a nações diferentes (um Estado multinacional), se estes emigraram de diversas nações (um Estado poliétnico), sempre e quando isso suponha um aspecto importante da identidade pessoal e da vida política.

\subsection{Estados Multinacionais e Estados Poliétnicos}

Um país que contém mais de uma nação não é uma nação-Estado, mas um Estado multinacional, no qual as culturas menores conformam as minorias nacionais. Muitas democracias ocidentais são multinacionais, a exemplo dos Estados Unidos (índios, descendentes de mexicanos - chicanos - os nativos havaianos, os esquimós do Alasca, etc.). Outras democracias ocidentais também são multinacionais, seja porque incorporaram à força povos indígenas (por exemplo, Nova Zelândia), ou porque se constituíram mediante federação, mais ou menos voluntária, de duas ou mais culturas europeias (por exemplo, Bélgica e Suíça). Muitos países 


\section{Humanos}

Democracia

do mundo são multinacionais no sentido de que suas fronteiras traçaram-se de forma que incluíram o território ocupado por culturas preexistentes que muitas vezes possuíam autogoverno (a exemplo do antigo bloco comunista).

Outra fonte de pluralismo cultural é a imigração. Um país manifestará pluralismo cultural se aceita como imigrantes a um grande número de indivíduos e famílias de outras culturas e lhes permite manter algumas de suas particularidades étnicas. $O$ autor distingue esse tipo de diversidade cultural daquela própria das minorias nacionais. Os grupos imigrantes nem são nações nem ocupam terras natais, destacando-se que sua especificidade se manifesta fundamentalmente em sua vida familiar e nas associações voluntárias, algo que não resulta contraditório com sua integração institucional (p. 29-31).

Segundo o autor, as minorias nacionais e grupos étnicos distinguem-se dos denominados novos movimentos sociais (associações e movimentos de gays, mulheres, etc.) que são marginalizados dentro de sua própria sociedade nacional ou de seu grupo étnico.

Algumas pessoas sugerem que uma concepção verdadeiramente liberal de pertencimento nacional deveria basear-se exclusivamente na aceitação dos princípios políticos e dos direitos democráticos, e não na integração em uma cultura determinada. Segundo o autor, isso é errôneo, pois o que distingue as nações cívicas das nações étnicas não é a ausência de todo componente cultural na identidade nacional, mas o fato de que qualquer pessoa pode integrar-se à cultura comum, seja qual for sua raça ou sua cor.

A imigração e a incorporação de minorias nacionais são as duas fontes mais comuns de diversidade cultural nos Estados modernos. $\mathrm{O}$ autor alerta que existem outros grupos culturais que não se ajustam claramente à categoria das minorias nacionais nem dos imigrantes voluntários. Por exemplo, os refugiados, pois vieram individualmente ou com suas famílias, mas não de forma voluntária (p. 45).

\subsection{Três Formas de Direitos Diferenciados em Função do Grupo}

Segundo o autor, são três as formas de cidadania diferenciada, ou seja, formas de direitos específicos em função de um pertencimento grupal (p. 46-55):

1) Direitos de autogoverno: A delegação de poderes às minorias nacionais, por meio de algum tipo de federalismo, o qual reparte poderes entre o governo central e as subunidades regionais (províncias/Estados). Uma das dificuldades do sistema federal é manter o equilíbrio entre a centralização e a descentralização, e também que suas concessões não se consideram uma medida temporária, nem um remédio para uma forma de opressão que talvez se possa eliminar. Tais direitos muitas vezes são descritos como sendo direitos intrínsecos e, portanto, permanentes.

2) Direitos poliétnicos: Apoio financeiro e proteção legal para determinadas práticas associadas com específicos grupos étnicos ou religiosos. A reivindicação por subvenção pública de suas práticas culturais inclui a subvenção de associações, revistas e festivais étnicos, arte e museus. Talvez a reivindicação mais controvertida dos grupos étnicos seja a relacionada com a extensão das leis e das disposições que contrariam suas práticas religiosas (por exemplo, as jovens muçulmanas que solicitaram na França a flexibilização das normas de indumentária escolar para que possam usar o chador). 
3) Direitos especiais de representação: Mandatos garantidos para grupos étnicos ou nacionais no seio das instituições centrais do Estado que os engloba. Para isso, os partidos políticos devem ser mais inclusivos. Muitas vezes os direitos de representação derivados do pertencimento a um grupo são uma resposta a algumas barreiras sistêmicas presentes no processo político que impedem que as opiniões e os pareceres do grupo em questão estejam devidamente representados.

\section{Direitos Individuais e Direitos Coletivos}

O terceiro capítulo explora a relação entre direitos coletivos e direitos individuais.

Os direitos coletivos podem se referir a diferentes situações:

1) Restrições internas: ao direito de um grupo a limitar a liberdade de seus próprios membros em nome da solidariedade do grupo ou da pureza cultural.

2) Proteções externas: ao direito de um grupo a limitar o poder político e econômico exercido sobre tal grupo pela sociedade da qual faz parte, com o objetivo de assegurar que os recursos e as instituições de que dependem a minoria não sejam vulneráveis às decisões da maioria.

Segundo o autor, tais proteções não estariam necessariamente em conflito com a liberdade individual. $O$ traço distintivo de uma teoria liberal dos direitos humanos das minorias é que esta aceita algumas proteções externas, mas resiste em aceitar as restrições internas.

\subsection{Restrições Internas e Proteções Externas}

Muitos liberais temem que os direitos coletivos reivindicados por grupos étnicos e nacionais sejam contrários aos direitos individuais. Conforme o autor, a retórica sobre direitos individuais versus direitos coletivos é de pouca ajuda, mostrando-se necessário distinguir entre dois tipos de reivindicações que um grupo étnico ou nacional poderia fazer (p. 58-60):

1) Reivindicação contra seus próprios membros. Objetiva proteger o grupo do impacto desestabilizador do dissenso interno (por exemplo, decisão de membros individuais de não seguir as práticas ou costumes tradicionais do grupo), ao que o autor denomina restrições internas, as quais dizem respeito a relações intragrupais (dentro do grupo).

2) Reivindicação contra a sociedade na qual está englobado. Objetiva proteger o grupo do impacto desestabilizador do dissenso externo (por exemplo, decisões políticas e econômicas da sociedade maior que engloba o grupo), ao que o autor denomina proteções externas, as quais dizem respeito a relações intergrupais (entre grupos).

$\mathrm{O}$ autor reconhece tanto as restrições internas quanto as proteções externas como direitos coletivos, mas que trazem diferentes questionamentos: nas restrições internas, o grupo étnico ou nacional pode pretender usar o poder do Estado para restringir a liberdade de seus próprios membros em nome da solidariedade do grupo, o que representa o perigo da opressão individual quando os direitos da coletividade prevalecem sobre os direitos dos indivíduos.

Assim, o autor emprega a terminologia restrições internas para aludir exclusivamente às situações nas quais as liberdades civis e políticas básicas dos membros do grupo se encontram restringidas. Já nas proteções externas, o grupo étnico ou nacional pode tratar de proteger sua existência e sua identidade específica limitando o impacto das decisões da sociedade na 


\section{Hireitos \\ Humanos e}

Democracia

qual está englobado. Isso também traz certos problemas, não de opressão individual dentro do grupo, mas de injustiça entre grupos. Um grupo pode ser marginalizado ou segregado para conservar a especificidade de outro grupo, a exemplo do apartheid na África do Sul, quando um grupo minoritário reivindicou uma proteção especial diante do conjunto da sociedade.

Segundo o autor, os três tipos de cidadania diferenciada em razão do grupo podem ser empregados para proporcionar as proteções externas (p. 61):

1) Direitos de autogoverno: conferem poderes a unidades políticas menores, de maneira que uma minoria nacional não pode ser subestimada ou superestimada pela maioria em decisões que são de particular importância para sua cultura, como as questões de educação, imigração, língua, etc.

2) Direitos poliétnicos: protegem práticas religiosas e culturais específicas que poderiam não estar adequadamente apoiadas pelo mercado (subvencionando programas que fomentem as línguas dos grupos) ou que estejam em desvantagem na legislação vigente (legislação sobre indumentária que entra em conflito com crenças religiosas).

3) Direitos especiais de representação: para os grupos dentro das instituições políticas do conjunto da sociedade é menos provável que uma minoria nacional ou étnica seja ignorada em decisões que afetem ao país.

É possível que os direitos poliétnicos sejam empregados para impor restrições internas. Por exemplo, minorias religiosas poderiam desejar o poder legal para impor a seus membros as práticas culturais tradicionais, como a critoridectomia. Teme-se que o multiculturalismo, levado a seu extremo lógico, possa justificar que cada grupo étnico tenha autoridade para impor suas próprias tradições a seus membros, ainda quando ditas tradições contradigam os direitos humanos básicos e os princípios constitucionais (p. 65).

Nesse contexto, o autor defende que em vez de garantir uma prioridade pouco justificada aos direitos coletivos sobre os direitos individuais, ou vice-versa, deveríamos distinguir as proteções externas e as restrições internas.

\subsection{A Ambiguidade dos Direitos Coletivos}

O autor entende que a expressão "direitos coletivos" é muito ampla, não logrando traçar a distinção entre restrições internas e proteções externas (p. 71).

Os individualistas aduzem que o indivíduo é moralmente anterior à comunidade: a comunidade importa unicamente porque contribui para o bem-estar dos indivíduos que a constituem. Se tais indivíduos consideram que já não vale a pena manter as práticas culturais existentes, então a comunidade não tem nenhum interesse independente em manter ditas práticas, e nenhum direito a impedir que os indivíduos as modifiquem ou as rechacem. Os individualistas, portanto repudiam a ideia de que os grupos étnicos e nacionais tenham qualquer tipo de direitos coletivos.

Pelo contrário, os coletivistas negam que os interesses de uma comunidade sejam reduzíveis aos interesses dos membros que a compõem. Equiparam os direitos coletivos aos direitos individuais, e os defendem de forma paralela. As teorias sobre os direitos individuais começam por explicar o que é um indivíduo, que interesses tem, e daí deriva um conjunto de 
direitos individuais que protegem tais interesses. De forma similar, os coletivistas começam por explicar o que é uma comunidade, que interesses tem, e daí origina-se um conjunto de direitos comunitários que protegem tais interesses.

A afirmação de que as comunidades têm interesses independentemente de seus membros é relevante para as restrições internas, pois pode explicar porque os membros de uma comunidade estão obrigados a manter práticas culturais. Não pode, contudo, explicar as restrições externas, ou seja, porque alguns direitos se distribuem desigualmente entre os grupos, porque os membros de um grupo reivindicam algo aos membros do outro grupo. A ideia de que os grupos prevalecem ante os indivíduos, ainda que fosse certa, não pode explicar por si mesma essa assimetria entre os grupos.

Assim sendo, coletivistas e individualistas divergem sobre a questão se as comunidades podem ter direitos ou interesses independentemente de seus membros individuais, o que constitui um dos mais antigos e venerados debates da filosofia política (p. 75).

\section{Repensando a Tradição Liberal}

O quarto capítulo (p. 77-109) faz uma relação histórica entre o liberalismo e os direitos das minorias, tentando explicar a influência no modelo liberal da concepção americana de uma Constituição cega em matéria de etnicidade, a qual foi configurada por fatores únicos, como a segregação racial e a magnitude da imigração, e que não são necessariamente aplicáveis a outros países, e sequer é válida para os Estados Unidos, pois ignora o status dos índios americanos, dos porto-riquenhos e de outros povos.

Assim, o autor conclui que as tradições políticas ocidentais têm sido conformadas pelas mesmas influências históricas que conformaram o pensamento liberal, e todas são culpáveis de sustentar supostos etnocêntricos, ou da excessiva generalização de casos particulares, ou de mesclar a estratégia política contingente com um princípio moral permanente, e que a tarefa de desenvolver uma teoria dos direitos das minorias consistente e baseada em princípios é uma tarefa que enfrentam apenas os liberais.

\section{Liberdade e Cultura}

O quinto capítulo analisa o papel da cultura na teoria democrática liberal, defendendo uma determinada visão do liberalismo, baseada no compromisso com a liberdade de eleição e com a autonomia pessoal, defendendo que tal visão se coaduna com o interesse pelo pertencimento cultural ou étnico e que exige levar tal fator em consideração. Ademais, defende que a eleição individual depende da presença de uma cultural societária, definida pela língua e a história, considerando que a maioria das pessoas sentem-se fortemente vinculadas com sua própria cultura.

O autor entende que o mundo moderno está dividido em culturas societárias, cujas práticas e instituições compreendem toda gama de atividades humanas, abarcando a vida pública e a vida privada. Tais culturas societárias estão caracteristicamente associadas com os grupos nacionais. Assim, a liberdade individual está intimamente vinculada com o pertencimento 


\section{Humanos e}

Democracia

a estas culturas, e o valor liberal da liberdade de eleição tem determinados pré-requisitos culturais, e por isso, as questões de pertencimento cultural devem ser incorporadas aos princípios liberais (p. 112).

Acerca do tema, Kymlicka questiona: Por que as pessoas deveriam ser livres para eleger seu próprio plano de vida? Sabemos que algumas pessoas podem tomar decisões imprudentes, perdendo tempo com objetivos triviais ou impossíveis. Então por que o governo não deveria intervir para nos proteger de cometer erros e nos obrigar a levar a verdadeira vida boa? Os governos podem não ser de confiança, alguns indivíduos têm necessidades particulares difíceis de serem tidas em conta, apoiar concepções opostas pode levar ao dissenso civil.

Para levar uma vida boa há duas condições prévias. A primeira é que dirijamos nossa vida desde dentro, de acordo com nossas convicções sobre o que dá valor à vida. A segunda é que somos livres para questionar estas crenças, para examiná-las à luz de qualquer informação, exemplo e argumento que nossa cultura possa nos proporcionar. A liberdade implica escolher entre diversas opções, e nossa cultura societária não apenas proporciona essas opções, como também faz com que sejam importantes para nós. As pessoas escolhem entre as práticas sociais do seu entorno, em função de suas crenças sobre o valor dessas práticas, o que consiste em compreender os significados que nossa cultura Ihe atribuem (p. 119-120).

Assim sendo, o autor entende que os liberais deveriam reconhecer a importância do pertencimento das pessoas a sua própria cultura, em virtude do papel que esta desemprenha no momento de possibilitar eleições individuais significativas e sustentar a própria identidade. Ainda que os membros de uma nação não compartilhem valores morais ou estilos de vida tradicionais, seguem tendo uma profunda vinculação com sua língua e sua cultura próprias, pois a identidade nacional já não repousa em valores compartilhados, mas reside fora da esfera normativa, o que proporciona um fundamento sólido para a autonomia e a identidade individual.

O pertencimento cultural oportuniza um contexto de eleição inteligível e assegura um sentimento de identidade e pertencimento, sentimento ao qual podemos recorrer para enfrentar questões acerca dos valores e projetos pessoais. Por outro lado, que a identidade nacional não requeira valores compartilhados explica porque as nações são as unidades apropriadas para a teoria liberal; os grupos nacionais oferecem um âmbito de liberdade e igualdade, assim como uma fonte de reconhecimento e confiança mútuos, que podem acomodar os inevitáveis desacordos e dissensos sobre as concepções de bem na sociedade moderna.

\section{A Justiça e os Direitos das Minorias}

O sexto capítulo explica três dos principais argumentos em favor dos direitos diferenciados em função do grupo para minorias nacionais e grupos:

1) Argumentos baseados na igualdade (p. 152-164): objetiva mostrar que as minorias têm de fazer frente a certas desvantagens injustas que podem ser retificadas mediante um direito diferenciado em função do grupo, pois a acomodação das diferenças constitui a essência da verdadeira igualdade, e para acomodar as diferenças são necessários direitos específicos em função do grupo, como a autonomia territorial, o direito ao voto, a representação ga- 
rantida nas instituições centrais, as reivindicações territoriais e os direitos linguísticos. Isso pode ajudar a corrigir as desvantagens das minorias, mitigando a vulnerabilidade das culturas minoritárias ante as decisões das maiorias. As proteções externas deste tipo asseguram que os membros de uma minoria tenham as mesmas oportunidades de viver e de trabalhar em sua própria cultura que os membros da maioria.

Poder-se-ia argumentar que as decisões sobre a língua de ensino e os serviços públicos deveriam ser determinados não mediante o reconhecimento oficial da existência de diversos grupos, mas simplesmente permitindo que cada subunidade política aplicasse sua própria política linguística, partindo de premissas democráticas. Se uma minoria nacional constitui a maioria na unidade ou subunidade pertinente, pode decidir que tal unidade adote sua língua materna como língua oficial, mas pode decidir porque existe uma maioria local, não porque o Estado a tenha reconhecido oficialmente como nação.

Por conseguinte, pergunta-se: O que seria uma forma justa de reconhecer línguas, traçar fronteiras e distribuir poderes? Para o autor, a resposta consiste em afirmar que deveríamos assegurar que todos os grupos nacionais tenham a possibilidade de se manter como cultura distinta, se assim o desejarem. Dessa forma, assegurar-se-ia a igual proteção dos traços positivos do pertencimento cultural para os membros de todos os grupos nacionais. Em uma sociedade democrática, a nação maioritária sempre receberá ajuda para sua língua e sua cultura societária, e terá também poder legislativo para proteger seus interesses em decisões que afetem sua cultura. A questão é se a imparcialidade exige que sejam concedidas às minorias nacionais as mesmas prestações e oportunidades. $\mathrm{O}$ autor entende que tal resposta deve ser afirmativa.

2) Argumentos baseados na história (p. 164-170): objetiva mostrar que as minorias têm certo direito histórico a um direito diferenciado em função do grupo, fundamentado em uma soberania prévia, em tratados ou em algum outro acordo ou precedente histórico, a exemplo dos direitos dos povos indígenas e do acordo mediante o qual dois ou mais povos decidem federar-se. O autor ressalta que seguramente alguns acordos históricos estão obsoletos, enquanto outros são manifestamente injustos, ou foram firmados compulsoriamente ou mesmo por ignorância. Por isso, questiona: Por que na atualidade os governos não deveriam se ater ao que exigem os princípios de igualdade, em lugar de cumprir o disposto em acordos antiquados e carentes de princípios? Uma das respostas consiste em considerar o suposto subjacente ao argumento da igualdade de que o Estado deve tratar aos seus cidadãos com igual respeito. Isso, no entanto, supõe determinar previamente quais cidadãos deveriam ser governados por cada Estado.

Segundo o autor, a igualdade e os argumentos históricos costumam produzir resultados similares, embora sejam diferentes. Aponta como dificuldades dos acordos históricos que muitas vezes são difíceis de interpretar e que na atualidade muitos seriam injustos diante da mudança das condições em que foram feitos, como mudanças no estilo de vida, variações demográficas. Afirma que as argumentações históricas são muito menos frequentes no caso dos grupos étnicos, pois aos imigrantes raras vezes é prometido algum direito especial antes da sua chegada ao novo país. Nesse sentido, defende a ideia de que, se queremos defender os direitos diferenciados em razão de um grupo, não devemos nos basear exclusivamente em 


\section{Humanos}

Democracia

acordos históricos, pois estes devem ser inevitavelmente interpretados, atualizados e revisados, razão pela qual a argumentação da igualdade e a argumentação histórica devem ser complementares.

3) Argumentos baseados na diversidade cultural (p. 170-173): objetiva mostrar que a reivindicação pelo valor intrínseco da diversidade cultural relaciona-se tanto com a igualdade quanto com as argumentações históricas. $O$ autor analisa a argumentação de que a diversidade cultural é valiosa, seja por criar um mundo mais interessante, seja porque outras culturas possuem modelos alternativos de organização social que podem resultar úteis se adaptados a novas circunstâncias. Embora concorde que há algo de certo em tal afirmação, entende que é errôneo dar-Ihe demasiada importância no momento de defender os direitos nacionais. Um dos problemas é que a diversidade cultural apenas beneficia a maioria de uma maneira superficial e geral, enquanto que os custos que esta representa para os membros individuais da maioria são, em muitas ocasiões, bastante elevados.

$\mathrm{O}$ argumento da diversidade traz outro problema adicional: Por que o valor da diversidade justifica a imposição de determinados custos sobre os membros da cultura maioritária? Nesse caso, por que o valor da diversidade não justifica também que seja imposta aos membros da minoria a obrigação de manter sua cultura tradicional? Por isso, o autor entende que a argumentação da diversidade não basta por si mesma para justificar os direitos das minorias nacionais, sendo improvável que as maiorias aceitem suas obrigações de justiça para com as minorias nacionais se não acreditam que tenham algo a ganhar nesse processo. Assim, a argumentação da diversidade funciona melhor se combinada com a argumentação da justiça.

A partir destes três argumentos, portanto, Kymlicka defende que o debate sobre os direitos das minorias não é uma questão sobre se é legítimo ou não apoiar as comunidades ou reconhecer as diferenças, mas sim sobre se se deve ou não apoiar o tipo concreto de diferença cultural e de comunidade característico das minorias nacionais. Alguns liberais admitem que é de justiça proporcionar às minorias nacionais a mesma ajuda que recebem as nações majoritárias. Por sua vez, alguns comunitaristas mostram-se receosos de aceitar as reivindicações das minorias nacionais, pois entendem que elas são praticamente o mesmo que os grupos étnicos ou os movimentos sociais (p. 180-181).

Ou seja, são formas de diferença e de comunidade que podem e devem se acomodar dentro do conjunto da sociedade mediante direitos específicos em função do grupo. Não estão dispostos a aceitar que as minorias nacionais sejam reconhecidas como sociedades separadas. As reivindicações das minorias nacionais e dos grupos étnicos traz um profundo desafio para todas as tradições políticas ocidentais, todas elas formadas, implícita ou explicitamente, pelas mesmas influências históricas que formaram o pensamento liberal.

\section{Assegurar a Voz das Minorias}

O sétimo capítulo aborda questões de representação política, especialmente nas propostas para garantir mandatos no corpo legislativo central para os membros de determinados grupos étnicos ou nacionais. Discute algumas das dificuldades práticas e teóricas de tais propostas, bem como traz formas alternativas para assegurar voz às minorias nas tomadas de de- 
cisão políticas. Aborda a tensão entre os direitos de autogoverno (que reclamam a delegação de poder do governo central para a comunidade minoritária) e os direitos de representação (que exigem que seja garantida a representação das minorias no governo central).

Conforme Kymlicka, muitas pessoas acreditam que, em primeiro lugar, dever-se-ia tentar colocar em prática as medidas para corrigir as insuficiências de representação de grupos concretos, e apenas no caso de que estas resultassem ineficazes ou funcionassem lentamente é que se deveria provar a representação de grupo. Alguns países, no entanto, ensaiaram essas medidas com resultados pouco alentadores, de maneira que provavelmente as reivindicações em favor da representação de grupo não desaparecerão. Assim sendo, é importante pensar que papel pode ter a representação de grupo em uma teoria democrática liberal.

\subsection{Por que a Representação de Grupo?}

Um dos argumentos sustenta que embora os homens brancos possam compreender os interesses das mulheres e dos negros, por exemplo, não se deve confiar a eles a defesa de tais interesses. $\mathrm{O}$ autor concorda que há algo de certo neste argumento, pois nossa capacidade de se colocar no lugar de outras pessoas tem limites, mesmo quando tentamos fazê-lo sinceramente, e também porque há limites ao grau em que a maioria das pessoas tenta sinceramente se colocar no lugar do outro. Tal ideia, todavia, padece de algumas inconsistências:

1) A idéia de que o legislativo deveria refletir a população em geral separa definitivamente da política eleitoral a eleição de representantes por loteria ou por mostra aleatória. [...]

2) O suposto de que os brancos não podem compreender as necessidades dos negros, ou de que os homens não podem compreender as necessidades das mulheres, pode se converter em um pretexto para que os homens brancos não se esforcem em entender ou representar as necessidades dos demais. [...]

3) O suposto segundo o qual os homens não podem compreender os interesses das mulheres é ambivalente, pois implica que as mulheres não podem compreender e representar os homens [...] (p. 193-194).

Tais dificuldades sugerem que se deveria prescindir da ideia da representação especular como teoria geral da representação. Há limites na medida em que as pessoas são capazes e estão dispostas a saltar as barreiras da experiência. A solução não está em aceitar tais limitações, mas em combatê-las para criar uma cultura política na qual as pessoas possam e estejam dispostas a se colocar no lugar dos demais, assim como a compreender realmente suas necessidades e interesses.

Segundo o autor, isso não é fácil: pode exigir mudanças no sistema educativo, na descrição que os meios de comunicação fazem de diversos grupos e no processo político para aproximá-lo de um sistema de democracia deliberativa, e ainda assim não se garantiria que os membros de um grupo pudessem compreender as necessidades de outro. Este é o desafio da empatia. Renunciar, porém, à posição de representação intergrupal é renunciar à possibilidade de uma sociedade na qual os cidadãos se comprometam em satisfazer às necessidades de cada um e a compartilhar o destino dos demais. 


\section{Humanos}

Democracia

\subsection{Valoração da Representação de Grupo}

Os direitos de representação de grupo apelam a algumas das práticas e princípios fundamentais da democracia representativa e, por outra parte, algumas formas de representação de grupo poderiam desempenhar um papel importante, ainda que limitado, dentro do sistema político democrático. Qualquer proposta de representação de grupo, no entanto, deve resolver diversas dificuldades, como a de identificar os grupos verdadeiramente desfavorecidos e a de assegurar que seus representantes cumpram com suas responsabilidades diante deles.

Alguns liberais opõem-se à representação de grupo baseando-se em que institucionalizar as diferenças de grupo e outorgar-Ihes relevância política teria graves consequências para a unidade social. A preocupação pela unidade social aparece sempre que se trata de direitos diferenciados em função do grupo. Ademais, as questões relativas à representação não podem se reduzir à composição do legislativo, a qual deve situar-se no contexto de outros mecanismos para representar os interesses de um grupo, como a impugnação legal da legislação desfavorável e a defesa dos interesses do grupo nos tribunais.

Nesse viés, a representação de grupo não é intrinsecamente não liberal ou antidemocrática. É uma ampliação plausível de nossas tradições democráticas existentes e em determinadas circunstâncias é a melhor maneira de assegurar que as minorias possam expressar adequadamente seus interesses e suas aspirações. É vital que as minorias disponham de procedimentos justos para que se escute sua voz no processo político, de modo que as propostas orientadas a lograr a representação de grupo Ihes proporcionem tais procedimentos (p. 208-209).

\section{A Tolerância a seus Limites}

O oitavo capítulo discute como deveriam responder os liberais a situações em que as minorias exigem o direito a restringir as liberdades civis e políticas básicas de seus próprios membros, pois uma teoria liberal dos direitos das minorias não pode justificar tais restrições internas, isto é, não pode aceitar a ideia de que resulta moralmente legítimo para um grupo oprimir a seus membros em nome da solidariedade grupal, da religião ou da pureza cultural. Os Estados liberais deveriam impor as normas liberais sobre as minorias não liberais? Isso traz complicadas questões sobre o significado da tolerância e de seus limites. Por isso, aborda a relação entre os valores de tolerância e autonomia individual na teoria liberal, destacando alguns fatores que devem ser levados em consideração no momento de avaliar a legitimidade da imposição de valores liberais às minorias não liberais.

Uma perspectiva liberal exige liberdade dentro do grupo minoritário e igualdade entre os grupos minoritários e majoritários (p. 212). Entre os liberais há um largo e crescente debate sobre qual é o valor fundamental da teoria liberal, a autonomia ou a tolerância. Consoante o autor, é preciso buscar formas pelas quais o liberalismo pode e não pode acomodar a grupos não liberais.

\subsection{Liberalismo e Tolerância}

Liberalismo e tolerância estão intimamente relacionados, tanto do ponto de vista histórico quanto conceitual. $O$ desenvolvimento da tolerância religiosa foi uma das raízes históricas do liberalismo. E se verdadeiramente consideramos o liberalismo uma extensão do princípio 
da tolerância religiosa, é importante reconhecer que, ao menos no Ocidente, a tolerância religiosa adquiriu uma forma específica, transformando-se na ideia de liberdade de consciência individual. Na atualidade, essa ideia consiste num direito básico individual à liberdade de culto, a propagar a própria fé, a mudar de religião ou mesmo renunciar a ela. Impedir que um indivíduo exerça tais liberdades implica violar um dos direitos humanos fundamentais.

Historicamente, os liberais têm uma noção muito específica de tolerância, que implica a liberdade de consciência individual e não a liberdade de culto coletiva. A tolerância liberal protege o direito dos grupos de não serem perseguidos pelo Estado. Limita o poder dos grupos não liberais no momento de restringir a liberdade dos seus próprios membros, assim como o poder dos Estados não liberais de restringir o culto coletivo. Na opinião do autor, isto demostra que, historicamente, para os liberais a autonomia e a tolerância têm sido as duas faces de uma mesma moeda. O que distingue a tolerância liberal é precisamente seu compromisso com a autonomia, ou seja, a ideia de que os indivíduos deveriam ter liberdade para atribuir valor e revisar potencialmente seus fins (p. 218).

\subsection{Como Acomodar as Minorias não liberais?}

A legitimidade de impor os princípios liberais a grupos não liberais depende de diversos fatores. A questão de como duas culturas ou dois países deveriam resolver as diferenças de princípios fundamentais é um assunto complicado. A maior parte dos liberais contemporâneos sustenta que os cidadãos de uma sociedade liberal, motivados pelos princípios liberais de justiça, não concedem relevância política ao seu pertencimento cultural. Segundo o autor, isso é um erro, pois os princípios liberais de justiça são coerentes com e requerem determinadas formas de status especial para as minorias nacionais.

Nos casos em que os membros de algumas culturas minoritárias rechaçam o liberalismo, os membros da maioria mais liberal terão de sentar-se com os membros da minoria nacional e encontrar alguma forma de convivência, pois os liberais não têm um direito automático de impor seus pontos de vista às minorias não liberais. Não obstante, têm o direito e a responsabilidade de identificar quais são realmente estes pontos de vista, pois as relações entre os grupos nacionais deveriam estar determinadas pelo diálogo. A contribuição da teoria liberal neste diálogo é explicar as implicações dos princípios liberais de liberdade e igualdade. Esse é o primeiro passo para iniciar o diálogo.

Ademais, o autor também reporta como fundamental não prejulgar a natureza não liberal de uma cultura minoritária determinada. A liberalidade de uma cultura é uma questão de grau. Todas as culturas têm aspectos não liberais, da mesma maneira que poucas são as culturas que reprimem totalmente a liberdade individual. Falar como se o mundo estivesse dividido entre sociedades completamente liberais de um lado e completamente não liberais por outro inibe a construção de um diálogo construtivo entre as culturas.

\section{Os Vínculos que Unem}

O nono capítulo ocupa-se da preocupação com a possibilidade de que os direitos diferenciados em função do grupo concedidos a minorias possam inibir o desenvolvimento de uma identidade compartilhada, necessária para uma ordem social estável. Ou seja, que a cidadania diferenciada em função de grupo fomente que os grupos se centrem em suas dife- 


\section{Humanos}

Democracia

renças e não nos seus objetivos compartilhados. Supõe-se que a cidadania tem uma função integradora, mas pode desempenhar tal função se a cidadania não é uma identidade legal e política comum? Argumenta que os direitos de representação e os direitos poliétnicos são coerentes com a integração dos grupos minoritários e que podem ajudar tal integração.

De outra parte, o direito de autogoverno seria uma ameaça à unidade social, pois propicia que a minoria nacional considere a si mesma como um povo separado que possui direitos intrínsecos a contar com seu próprio governo. Negar o direito ao autogoverno, no entanto, também pode ameaçar a unidade social, causando uma separação/independência. Por isso, uma das principais tarefas dos liberais é identificar as bases da unidade social nos Estados multinacionais.

\subsection{A Importância da Cidadania}

É possível seguir falando de cidadania numa sociedade em que os direitos se distribuem em razão do pertencimento a um grupo? Para o autor, a afirmação de que a cidadania diferenciada é uma contradição resulta exagerada, pois se ela é definida como a adoção de direitos poliétnicos, de representação ou de autogoverno específicos em função do grupo, então praticamente todas as democracias modernas reconhecem algum tipo deles, pois o conceito de cidadania hoje é muito mais diferenciado e muito menos homogêneo do que se supõe, citando Parekh. Já consoante os críticos da cidadania diferenciada, ela não proporciona uma experiência compartilhada nem um status comum, pois seria outro fator de desunião ao invés de cultivar a unidade diante da crescente diversidade social, de modo que a cidadania deveria ser um lugar no qual as pessoas superassem suas diferenças e pensassem no bem comum de todos os cidadãos.

Nesse sentido, o autor defende que a saúde e a estabilidade das democracias modernas dependem das qualidades e atitudes de seus cidadãos:

* do sentimento de identidade e de como consideram a outras formas de identidade nacional, regional, étnica ou religiosa que potencialmente possam competir com a sua,

* de sua capacidade de tolerar e de trabalhar com pessoas diferentes,

* do seu desejo de participar do processo político para promover o bem público e de apoiar as autoridades públicas responsáveis,

* da sua vontade de demonstrar comedimento e de assumir sua responsabilidade pessoal em suas exigências econômicas, assim como as eleições pessoais que afetem a sua saúde e o seu entorno,

* do seu sentido de justiça e de seu compromisso com uma distribuição equitativa dos recursos (p. 241-242).

Sem tais qualidades, a capacidade de progresso das sociedades democráticas diminui. $O$ auge das reivindicações baseadas no grupo fará com que se deteriore ainda mais o sentimento compartilhado de finalidade cívica e de solidariedade? Para responder a tal pergunta é preciso partir da distinção entre as três formas de cidadania diferenciada.

\subsection{Autogoverno e Separatismo}

As reivindicações de autogoverno refletem um desejo de debilitar os vínculos com essa comunidade política, questionando sua própria autoridade e permanência. Sua demanda básica não é simplesmente que alguns grupos estejam em situação de desvantagem 
dentro da comunidade política (direitos de representação), ou que a comunidade política é culturalmente diversa (direitos poliétnicos). O autogoverno reivindica que haja mais de uma comunidade política, e que a autoridade do Estado em seu conjunto não prevaleça sobre a autoridade das comunidades nacionais que o constituem. Se a democracia é o governo do povo, as minorias nacionais afirmam que há mais de um povo, cada um dos quais tem direito a se governar por si mesmo.

Assim, na sistemática do autogoverno, as pessoas são divididas em povos separados, cada um dos quais tem seus próprios direitos históricos, seus territórios e suas competências de autogoverno e, por conseguinte, sua própria comunidade política. Cada um desses povos pode considerar que sua própria comunidade política é a fundamental, e que o valor e a autoridade do conjunto da federação são secundários.

O autor considera improvável que a concessão de direitos de autogoverno a uma minoria nacional possa ter uma função integradora, pois geraria um tipo de cidadania dual, assim como potenciais conflitos sobre com qual comunidade os cidadãos sentem-se mais identificados. Entende que os Estados democráticos multinacionais que reconhecem os direitos de autogoverno são, aparentemente, não estáveis. Cita o argumento de Stuart Mill, segundo o qual uma democracia liberal estável deve ser um Estado-nação com uma cultura nacional única, e se as minorias nacionais não estão dispostas a assimilar, devem separar-se e criar seu próprio Estado. Em relação a isso, entende que a separação/independência nem sempre é possível ou desejável, a exemplo dos povos indígenas, que teriam problemas para construir Estados independentes viáveis (p. 254).

\subsection{As Bases da Unidade Social em um Estado Multinacional}

Quais as possíveis fontes de unidade num Estado multinacional que no lugar de negar, afirma suas diferenças nacionais? Não existem respostas óbvias nem fáceis para tal pergunta. Conforme o autor, uma possível resposta talvez seja que a unidade social depende dos valores compartilhados. Os cidadãos de qualquer democracia moderna podem compartilhar determinados valores políticos. Dessa forma, o ingrediente que falta parece ser a ideia de identidade compartilhada. Uma identidade cívica compartilhada que transcenda as identidades nacionais rivais. Nos Estados-nação, a identidade compartilhada deriva da história, da língua, da religião comum, justamente o que não é compartilhado num Estado multinacional.

O autor defende que existe uma forma viável de promover um sentimento de solidariedade e de finalidade comum em um Estado multinacional: acomodar e não subordinar as identidades nacionais. As pessoas de diferentes grupos nacionais somente compartilharão uma lealdade para com o governo geral se a percebem como o contexto em que se alimenta sua identidade nacional e não como o contexto que a subordina (p. 259).

Isso é muito mais complicado em países que não são apenas multinacionais, mas também poliétnicos, por exemplo, que albergam muitos grupos nacionais e indígenas. Nesse caso, necessitamos do que Taylor denomina de uma teoria da diversidade profunda, pois não apenas devemos acomodar diversos grupos culturais, mas também as múltiplas formas pelas quais os membros de tais grupos vinculam-se ao governo geral. Assim, as pessoas não apenas perten- 


\section{Humanos e}

Democracia

cem a comunidades políticas separadas, como também pertencem a elas de diferentes maneiras. Isso significa que os membros de um Estado multinacional e poliétnico não apenas devem respeitar a diversidade, mas também devem respeitar diversos enfoques sobre a diversidade.

Uma sociedade baseada na diversidade profunda é improvável que se mantenha unida, a menos que os cidadãos a valorizem por si mesma e queiram viver em um país com diversas formas de pertencimento cultural e político. Isso posto, para que os cidadãos queiram manter unido um Estado, não apenas devem valorizar a diversidade profunda em geral, mas também os grupos étnicos e as culturas nacionais concretas com as quais compartilham o país.

Em nome do fortalecimento de uma identidade cívica, muitos liberais defendem o princípio da cidadania comum. Segundo o autor, as reivindicações de direitos poliétnicos dos grupos imigrantes e desfavorecidos são, fundamentalmente, demandas de inclusão para lograr a plena participação no conjunto da sociedade. Considerar que são uma ameaça à estabilidade ou à solidariedade é pouco plausível e reflete ignorância e intolerância em relação a tais grupos. Já os direitos de autogoverno sim poderiam configurar uma ameaça à unidade social, por serem potencialmente desestabilizadores. Um dos desafios fundamentais dos pensadores liberais, portanto, é identificar os elementos de coesão que levariam à unidade em um Estado democrático multinacional (p. 263).

\section{Conclusão}

Kymlicka, em seu último capítulo (p. 265-267), constata que a globalização em muitos casos tem propiciado às minorias manterem uma identidade e uma vida grupal distinta, fazendo com que o mito de um Estado culturalmente homogêneo seja cada vez mais irreal, de modo a forçar que a maioria dentro de cada Estado seja mais aberta ao pluralismo e à diversidade, razão pela qual os desafios do multiculturalismo continuam existindo.

O autor também faz algumas especulações acerca do futuro da cidadania multicultural, lembrando que o final do século 20 foi descrito como "a era da migração", porque grandes quantidades de pessoas atravessavam as fronteiras, fazendo com que praticamente todos os países fossem mais e mais poliétnicos. Também foi descrito como "a era do nacionalismo", uma vez que em todo o mundo é cada vez maior o número de grupos que se mobilizam e afirmam sua identidade. Em consequência de tudo isso, em muitos países a vida política vem sendo questionada por uma nova "política da diferença cultural". Com o fim da guerra fria, as reivindicações de grupos étnicos e nacionais passaram ao primeiro plano da vida política, tanto no âmbito interno quanto no âmbito internacional.

Para muitas pessoas, essa nova "política da diferença" representa uma ameaça à democracia liberal. Embora não todas, muitas reivindicações dos grupos étnicos e nacionais são condizentes com os princípios liberais de liberdade individual e justiça social. Isso não significa que essas questões possam ser resolvidas de forma definitiva, pois o que está em jogo é demasiado complicado para tanto, mas é possível gerir de maneira pacífica e justa, se partirmos do pressuposto de que existe um certo grau de boa vontade.

Em várias partes do mundo os grupos não estão motivados pela justiça, mas pelo ódio e pela intolerância, e por isso não têm nenhum interesse em tratar aos demais com boa vontade. Em tais circunstâncias, a probabilidade de que os grupos étnicos e nacionais abusem de seus direitos e de seus poderes é muito elevada. A vida política tem uma ineludível dimensão 
nacional, tanto em relação às fronteiras e à distribuição de poderes quanto em relação às decisões sobre a língua das escolas, os tribunais e as burocracias, ou na eleição das festas públicas. Ademais, tais aspectos ineludíveis da vida política resultam altamente vantajosos para os membros das maiorias.

Algumas medidas para evitar injustiças podem incluir os direitos poliétnicos e de representação para acomodar os grupos étnicos e outros grupos desfavorecidos dentro de cada grupo nacional, assim como os direitos de autogoverno para permitir que seja possível a autonomia das minorias nacionais junto a autonomia das maiorias. Sem tais medidas, falar de "tratar as pessoas como indivíduos" não é mais que uma maneira de tapar as injustiças étnicas e nacionais.

Esses direitos devem respeitar duas restrições, pois precisam ter alguns limites: os direitos das minorias não devem permitir que um grupo domine a outros grupos e os direitos das minorias não devem permitir que um grupo oprima os seus próprios membros. Em outras palavras, os liberais deveriam tentar assegurar que existe igualdade entre os grupos, assim como liberdade e igualdade dentro dos grupos. Dentro desses limites, os direitos das minorias podem ocupar um valioso papel no contexto de uma teoria da justiça liberal em sentido amplo. De fato, o liberalismo deve tê-las em conta se não quiser ser condenado ao ostracismo em muitas partes do mundo.

Nesse contexto, nos lugares onde tradicionalmente nasceu a teoria liberal (Inglaterra, França e Estados Unidos), os direitos das minorias nacionais têm sido ignorados, ou tratados como meras curiosidades ou anomalias, algo especialmente aplicável a reivindicações dos povos indígenas. Os direitos das minorias são fundamentais para o futuro da tradição liberal em todo o mundo. Em muitos países, incluindo as incipientes democracias da Europa Oriental, África e Ásia, o status das minorias nacionais e dos povos indígenas é, provavelmente, a questão mais polêmica.

As pessoas desses países buscam nas obras dos liberais ocidentais um guia que thes indique os princípios do constitucionalismo liberal em um Estado multinacional, mas sobre essa questão a tradição liberal somente oferece conselhos confusos e contraditórios. O pensamento liberal acerca dos direitos das minorias tem pecado ao partir de supostos etnocêntricos, de generalizações excessivas de casos particulares, ou de misturar a estratégia política com o reforço de um princípio moral. Isso reflete-se claramente na ampla gama de políticas historicamente adotadas pelos Estados Unidos com respeito aos grupos étnicos e nacionais, políticas que vão desde a assimilação obrigada até a segregação forçada, desde a conquista e a colonização até o federalismo e o autogoverno.

Kymlicka, portanto, afirma que disso derivaram graves injustiças contra as minorias étnicas e nacionais em muitas democracias ocidentais, mas o fracasso no momento de desenvolver um enfoque consistente e baseado nos princípios dos direitos das minorias pode levar a custos ainda maiores nas novas democracias emergentes. Na atualidade, o destino dos grupos étnicos e nacionais de todo o mundo está nas mãos de nacionalistas xenófobos, de extremistas religiosos e de ditadores militares. Por fim, entende que para que o liberalismo tenha possibilidade de se estabelecer nesses países, será preciso abordar explicitamente as necessidades e aspirações das minorias étnicas e nacionais.

\section{Referência}

KYMLICKA, Will. Ciudadanía multicultural. Una teoría liberal de los derechos de las minorías. Barcelona: Ediciones Paidós, 1996. 